DOI: 10.12731/2227-930X-2018-4-153-166 УДК 656.07

\title{
СИСТЕМЫ АВТОМАТИЧЕСКОЙ ИДЕНТИФИКАЦИИ КАК СПОСОБ ПОВЫШЕНИЯ ЭФФЕКТИВНОСТИ РАБОТЫ ПАССАЖИРСКОГО ТРАНСПОРТА
}

\section{Шавыраа Ч.Д.}

В последние годы перед городами стоит острая проблема повышения эффективности работы городского пассажирского транспорта за счет эффективного использования имеющегося в наличии подвижного состава. На автобусных маршрутах г. Kblзыл работают перевозчики различных форм собственности, $u$ контроль их работь является приоритетной, т.к. от этого зависит соблюдение расписания движения, выход на линию, анализ качества обслуживания пассажиров и т.д. Внедрение диспетчерских систем оперативного управления позволят производить контроль над работой перевозчиков различных форм собственности, корректировать их работу и предоставлять отчётность о выполнении транспортной работы за заданный период.

Цель. В данной работе изучень основные диспетчерские системы оперативного управления, в частности система радиочастотной идентификации.

Методы. В статье рассматриваются методы автоматической идентификации, принциичальная схема работы системы автоматической идентификации, критерии оптимальности марирутной сети при использовании данных систем.

Результат. Использование автоматической идентификации транспортных средств позволит диспетчерским службам следить за работой автобусов МУП, он также важен при перевозке до места отдыха детей (икольные, пришкольные лагеря, летние оздоровительные лагеря), которые находятся за пределами населенных пунктов. 
Область применения результатов. Установлено, что радиочастотная идентификация помогает при применение диспетчерских навигачионных систем. Совместное их использование позволяет устранить некоторые запаздывания диспетчерских навигационных систем.

Ключевые слова: управление; организация; перевозки; система; автоматизаиия.

\section{AUTOMATIC IDENTIFICATION SYSTEMS AS A WAY TO IMPROVE THE EFFICIENCY OF PASSENGER TRANSPORT}

\section{Shavyraa Ch.D.}

In recent years, the cities are facing an acute problem of increasing the efficiency of urban passenger transport through the effective use of existing rolling stock. On the bus routes of Kyzyl, carriers of various forms of ownership work, and the control of their work is a priority, since it depends on compliance with the timetable, access to the line, analysis of the quality of passenger service, etc. The implementation of operational control dispatching systems will allow control over the work of carriers of various forms of ownership, adjust their work and provide reporting on the performance of transport work for a given period.

Purpose. In this paper, we studied the basic dispatching systems of operational management, in particular, the radio frequency identification system.

Methods. The article discusses the methods of automatic identification, a schematic diagram of the operation of the automatic identification system, criteria for the optimality of the route network when using these systems.

Result. The use of automatic vehicle identification will allow dispatching services to monitor the work of MUP buses, it is also important when transporting children to places of rest (school, school camps, summer recreation camps) that are outside the settlements. 
Practical implications. It is established that radio frequency identification helps with the use of dispatching navigation systems. Using them together allows you to eliminate some delays in dispatcher navigation systems.

Keywords: management; organization; transportation; system; automation.

\section{Введение}

Безопасное и своевременное обслуживание пассажиров, соблюдение графика движения транспортных средств, оперативный контроль над работой перевозчиков различных форм собственности невозможен без использования диспетчерских систем оперативного управления. В связи с тем, что на маршрутах г. Кызыл работают мелкие перевозчики, которые имеют по 1-2 микроавтобуса, все основные маршруты проложены через главную улицу г. Кызыл (ул. Кочетова), идет конкуренция не за рынок оказания транспортных услуг, а конкуренция на рынке.

Важным вопросом для горожан является качественное и своевременное обслуживание, т.к. в часы «пик» микроавтобусы не справляются с большим пассажиропотоком. Идет перегруз, нет возможности уехать на работу воспитателям детских садов (рабочий день начинается в 7 ч. утра), нет возможности пенсионерам получить талоны к стоматологу и. т.д.

В некоторых участках города, где отсутствуют камеры наблюдения, микроавтобусы могут развивать скорость до 70 км/ч, с переполненным салоном. Микроавтобусы типа «Газель» не предусмотрены для перевозки стоящих в салоне пассажиров, но в часы пик у некоторых перевозчиков в салоне могут находиться более 20 человек. При резком торможении стоящие пассажиры могут получить травмы, т.к. в салоне невозможно стоять в полный рост, не предусмотрены держатели.

Водители, для перехвата пассажиров в летнее время и выходные дни, устраивают «гонку» за пассажирами. Остановка для посадки и высадки пассажиров в непредусмотренном для этого месте, объезд сотрудников ГИБДД - вот основные проблемы, которые существуют в системе пассажирских перевозок в г. Кызыл. 


\section{Цель исследования}

Изучая свойства диспетчерских систем, можно формулировать и алгоритмы построения систем функционального контроля с гарантией обнаружения ошибок в контролируемых схемах. В данной работе изучены основные диспетчерские системы оперативного управления, в частности система радиочастотной идентификации.

\section{Материалы и методы исследования}

\section{Основные диспетчерские системы оперативного управления}

Использование навигационных систем на транспорте в РФ основывается на Постановлении Правительства Российской Федерации № 641 от 25.08.08 [5, 19]. Навигационные системы имеют для городов, населения, предприятия огромное значение, т.к. они помогают производить контроль работы автобусов, корректировку работы при дорожно-транспортных происшествиях, оказание помощи при аварийных ситуациях. Особая актуальность применения данных систем при организации пассажирских перевозок, т.к. города имеют разветвленную дорожную сеть. Контроль только в одной точке невозможен, маршруты автобусов могут быть проложены по всему городу. Быстрое реагирование на нарушение графиков и планов движения общественного транспорта, проводить анализ эффективности работы транспорта, получать объективную информацию о работе автобусов-вот перечень немаловажных факторов, которые так необходимы в наше время.

В настоящее время для автоматической идентификации могут использоваться следующие методы $[2,10]$ :

- Считывание акустико-магнитной информации. Метод основан на применении пластинки с намагниченным элементом (магнитной картой). Данная магнитная карта, как магнитофонная лента, имеет запись необходимых данных. Данный метод получил распространение в основном для доступа к предоставлению определенных услуг (дебетовые карты, карты доступа и т. п.). 
- Радиочастотная идентификация. На объекте размещается маломощный радиопередатчик, сигнал вызова считывается ридером и он передает записанную в памяти информацию.

- Оптическое распознавание специальных знаков (штрих-код). Данный метод распространен редко, т.к. является довольно ненадежным как на этапе считывания, так и на этапе распознавания. Штрих-код обычно выполняется в виде буквенно-цифровых символов транспортных этикеток, и стирание некоторых символов может привести к трудности распознавания.

- Биометрическая идентификация основана на измерении уникальных физических характеристик субъектов системы и отличается высокой степенью достоверности идентификации, неотделимостью биометрических признаков от субъекта и высокой сложностью их фальсификации.

Из рис. 1.1 видно, что только методы радиочастотной идентификации могут менять данные идентификатора с дальнего до ближнего действия. Сбор информации также более доступен. Радиочастотная идентификация имеет более широкие возможности, которые могут быть использованы для выполнения операций по доставке груза или пассажиров.

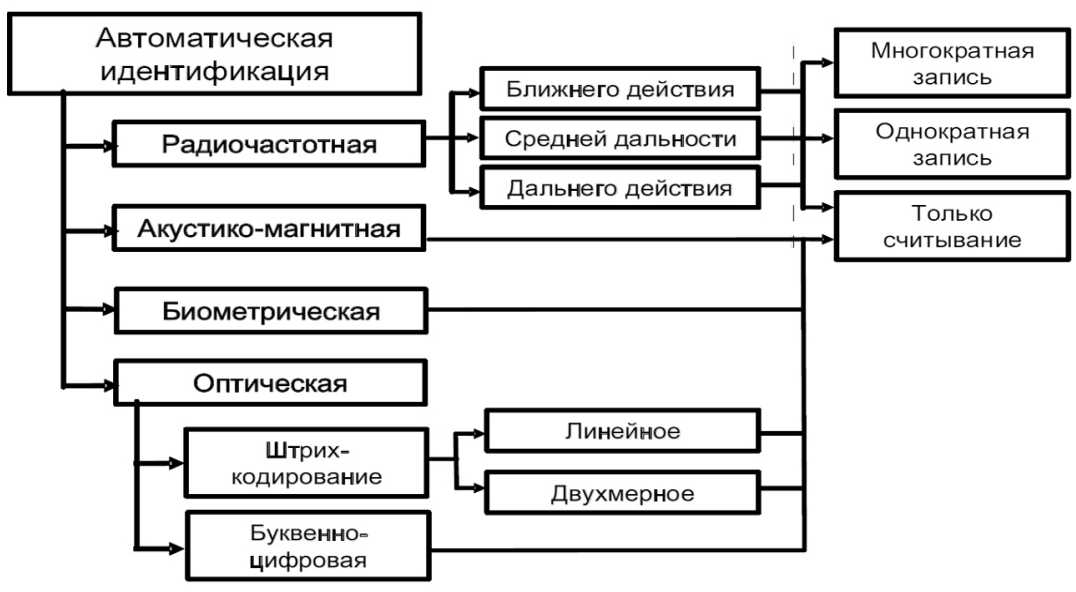

Рис. 1.1. Методы автоматической идентификации [2.3] 
Схемой работы системы автоматической идентификации можно ознакомиться на рис. 1.2.

Идентификатор устанавливается на объекте, в данном случае на транспортном средстве. Имеется считыватель, который распознает и передает информацию для обработки в базу данных. В процессе обработки данных идентификатора с использованием базы данных идентификаторов выполняются процедуры аутентификации и авторизации $[2,5]$.

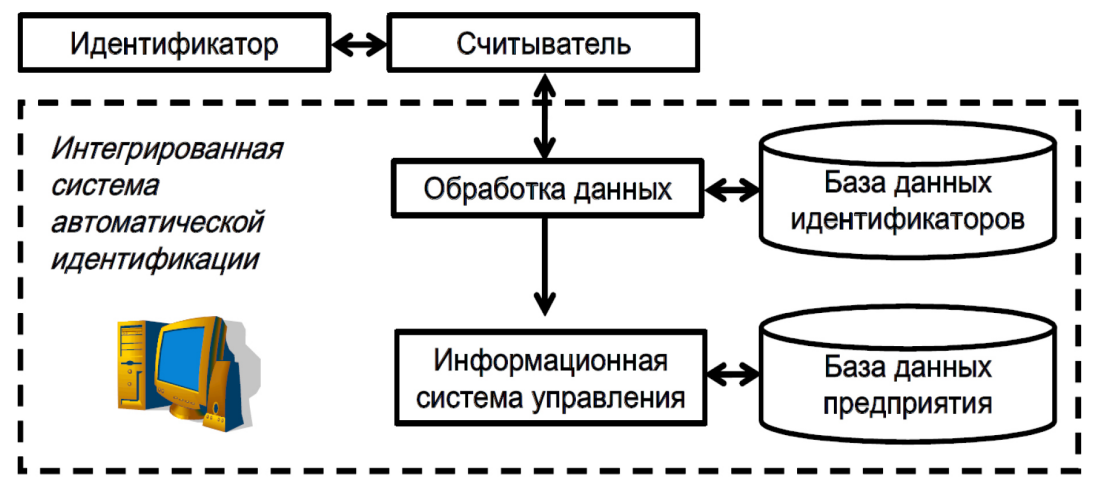

Рис. 1.2. Принципиальная схема работы системы автоматической идентификации

База данных идентификаторов может служить физическим ресурсом организации пассажирских перевозок, которая помимо идентификации объекта может определить принадлежность транспортного средства определенному перевозчику. Это помогает Администрации города решать спорные вопросы при выплате компенсации за проезд социальных слоев населения.

Следующим логическим шагом является организация доступа к базе данных идентификаторов через глобальную компьютерную сеть или с помощью прямого модемного соединения, чтобы не только диспетчеры могли наблюдать за работой перевозчиков в режиме реального времени, но и пассажиры могли контролировать работу автобусов с помощью приложений, которые можно скачать на телефон. 
На основании результатов авторизации данные идентификатора используются в информационной системе управления организации для выполнения тех или иных действий $[4,6,14]$.

Широкое использование методов автоматической идентификации, стандартизация оборудования для распознавания, распространение доступного программного обеспечения электронной идентификации позволяют проводить легкое управление логистическими операциями предприятий, складов, грузовых и пассажирских терминалов.

Средства и технологии автоматической идентификации из области специального применения переходят в повседневную жизнь людей: при покупке товаров в магазинах, посадке в самолет в аэропорту, использовании автомобиля, компьютера, заменяют ключи для входа в помещения и т. д.

Проектирование, внедрение и использование системы автоматической идентификации зависят от таких параметров, как развитие транспортной сети города, расценки оператора за сотовую связь $[11,13,15,17]$.

Система управления работой перевозчиков с помощью радиочастотной идентификации позволяет получать необходимую информацию о работе перевозчиков, вести учет выполненной работы и потребляемых ресурсов. Перевозчики, в свою очередь, выполняют работу точно в срок, и данная система позволяет дисциплинировать работу перевозчиков.

\section{Расчет целевой функции, как критерия оптимальности маршрутной сети}

Результаты использования диспетчерских систем можно выразить в таких показателях, как организационная эффективность системы обслуживания, минимизация затрачиваемого времени, расчетной вместимости транспортных средств, работающих на маршрутах, и количества необходимых автобусов на каждом маршруте.

а) Показатель организационной эффективности системы обслуживания населения - отношение фактического уровня обслуживания к нормативному $[18,20]$ : 


$$
\mathrm{K}_{1}=\frac{\text { Хфак }}{\text { Хнорм }}
$$

б) Показатель минимизации затрачиваемого времени пассажирами на городских маршрутах [18];

$$
\kappa 2=\sum Q_{\mathrm{ij}} * T_{\mathrm{ij}} \rightarrow \min ,
$$

в) Показатель расчетной вместимости ПС на каждом маршруте [18]:

$$
\text { К3 }=Q_{\text {ijмах }} * I,
$$

г) Показатель количества автобусов для работы на каждом маршруте [18]:

$$
\text { К_4 }=t_{\text {об }} / I=\left(2 L_{\mathrm{M}}\right) /\left(V_{\ni} I\right)=\left(2 L \mathrm{M} Q_{\text {іјмах }}\right) /\left(V_{\ni} q_{\text {расч }}\right),(1.4)
$$

где: $t_{\text {об }}$ время оборота; $V_{\text {э }}$ - скорость эксплуатационная; $L_{\text {м }}-$ длина маршрута.

Накопление статического материала по данным показателям для всех маршрутов городского пассажирского транспорта позволит делать выводы о ресурсоемкости системы по повышению организации транспортного обслуживания населения, о степени выполнения норм по пассажирским перевозкам и о размерах компенсаций, штрафов, других видов стимулирования различных видов деятельности $[1,9,16]$.

Большой объем требуемых системных исследований и разработок от уровня всей системы до структуры и функций каждого из образующих ее элементов, в которые входят показатели организационной эффективности, минимизации затрачиваемого времени, а также денежных средств пассажиров (оптимизация маршрутной сети), расчетная вместимость и количество требуемых автобусов позволят наиболее целесообразно использовать ПС [7, 8]. При этом качество пассажирских перевозок будет повышаться, т.к. система автоматической идентификации позволит следить за работой перевозчиков различных форм собственности. Также немаловажным фактором является отслеживание работы перевозчиков, и не просто контроль, а соблюдение расписания движения, помощь при авариях и ДТП, замена транспортных средств при поломках на линии. Все это является не только заботой о пассажирах, но и 
реальная помощь при вызове эвакуатора, кареты первой медицинской помощи, которые так необходимы водителям.

Полезность радиочастотной идентификации объясняется тем, что она позволяет раскрыть принципы решения проблемы, которые являются общими для множества организаций и предприятий при организации пассажирских перевозок.

В современных условиях часты ситуации, когда становится трудно выполнять рейсы точно по расписанию из-за влияния многих факторов на движение подвижного состава. Тем не менее, необходимо стремиться к использованию передовых средств и методов по организации, управлению, мониторингу и координации пассажирских перевозок [2, 3, 4].

\section{Результат и обсуждение}

Использование автоматической идентификации транспортных средств позволит диспетчерским службам следить за работой не только государственных автобусов, он также важен при перевозке до места отдыха детей (школьные, пришкольные лагеря, летние оздоровительные лагеря), которые находятся за пределами населенных пунктов. Считывание информации при передвижении транспортных средств по маршруту при перевозке школьников на экскурсии, соревнования в близлежащие города позволят родителям с помощью телефонов и других средств видеть маршрут движения в любое удобное для них время $[1,10,12]$. Поэтому особое место должно быть отведено методам радиочастотной идентификации.

\section{Заключение}

Для управления работой городского транспорта должна использоваться система, оснащенная современными техническими средствами контроля работы автобусов, оперативной передачи данных между перевозчиками и диспетчерским пунктом, интегрированная в информационную систему управления работой автопредприятий и городских служб управления транспортом [2]. 
Особая роль современных диспетчерских систем состоит в том, что можно не только контролировать работу перевозчиков различных форм собственности, но и следить за графиком работы, оказывать помощь водителям при экстренных ситуациях (когда происходит ДТП и другие аварийные ситуации), выпуск транспортных средств, взамен вышедшим из строя при поломках.

При сдаче документов для получения субсидий по выполненным социальным перевозкам, диспетчерские системы позволят получить результаты выполненной транспортной работы по каждому водителю, бригаде, колонне, предприятию или в целом по городу. При применении данной системы можно говорить о качестве обслуживания пассажиров городским пассажирским транспортом.

Таким образом, системы автоматической идентификации при одновременном использовании с диспетчерскими навигационными системами

Дает возможность контролировать работу операторов, оказывать помощь водителям при аварийных ситуациях, вести учет проделанной работы, помощь бухгалтерам при подсчете заработной платы (сдельная оплата труда), получение информации для населения о перевозчиках, графиках работы ПС. С каждым годом программу можно обновлять и получать более широкие возможности данных систем.

\section{Список литературы}

1. Воробьев А.И. Процесс информационного обмена в рамках комплексной автоматизированной системы управления дорожным движением / А.И. Воробьев, Г.В. Власенко // Автотранспортное предприятие. 2013. № 8. С. 27-29.

2. Горев А.Э. Информационные технологии на транспорте. Электронная идентификация автотранспортных средств и транспортного оборудования: учеб. пособие для студентов специальностей 190701 - организация перевозок и управление на транспорте, 
190702 - организация и безопасность движения (автомобильный транспорт); СПбГАСУ. СПб., 2010. 96 с.

3. Горев А.Э. Основные принципы организации приоритета транспорта общего пользования // Путевой навигатор Издательство: Ассоциация «Некоммерческое партнерство «Объединение участников дорожно-мостовой отрасли «Дормост» (Санкт-Петербург) 2018, С. 47-55.

4. Горев А.Э. Повышение эффективности транспортных систем путем развития ИТС. Современный транспорт // Сборник трудов № 17. Международная академия транспорта, 2014, С. 10-14.

5. Емельянова В.Г. Применение системы «ГЛОНАСС» на автомобильном транспорте как один из способов обеспечения безопасности дорожного движения / Актуальные вопросы технических наук (II): материалы междунар. заоч. науч. конф.(г. Пермь, февраль 2013 г.). Пермь: Меркурий, 2013. iv, С. 85-88.

6. Жанказиев С.В. Интеллектуальные транспортные системы. Пути развития // Информационные технологии и инновации на транспорте: материалы 2-ой Международной научно-практической конференции. Под общей редакцией А.Н. Новикова. 2016. С. 3-9.

7. Ларин О.Н. Совершенствование маршрутных сетей крупных городов / О.Н. Ларин, А.А. Кажаев; М-во образования и науки Рос. Федерации, Юж.-Урал. гос. ун-т, каф. «Эксплуатация автомобил. трансп.». Челябинск: ЮУрГУ, 2013. 147 с.

8. Новиков А.Н. Оптимизация маршрутов пассажирских перевозок в городе Орле / А.Н. Новиков, А.В. Кулев, А.А. Катунин, М.В. Кулев, Н.С. Кулева // Мир транспортных и технологических машин. 2015. № 3 (50). C. 115-122.

9. Приходько В.М., Жанказиев С.В. На пути к автономным транспортным средствам /Научные школы МАДИ. М.: Издательство «ПЕРО». 2016. $152 \mathrm{c}$.

10. Шадрин С.С., Иванов А.М. Возможности использования бортовых сетей передачи данных автомобильных транспортных средств в задачах интеллектуальных транспортных систем //Автотранспортное предприятие. 2014. № 5. 
11. Сайт фирмы Siemens VDO Automotive: http://www.hpw.ch/ (дата обращения 26.11.2018)

12. Сайт фирмы MDV. http://www.mentzdv.de/en/ (Дата обращения 28.11.2018).

13. Best practice guide. Public transport-planning the Networks/Gustav Nielsen, 2005. Oslo: Hi-Trans $180 \mathrm{p}$.

14. Gorev A., Solodkij A. System Approach to Elimination of Traffic Jams in Large Cities in Russia. World Applied Sciences Journal 23 (8): 2013: pp. $1112-1117$.

15. Evaluation of bus priority strategies in coordinated traffic signai systems/Johan Wahlstedt. Royal institute of Technology, School of Architecture and the Built Environment, Department of Transport Science, Division of Traffic and Logistics. Stockholm: 2014. 181 p.

16. Huvarinen Y., Svatkova E., Oleshchenko E., Pushchina S. Road safety audit // Transportation Research Procedia 2017, pp. 236-241.

17. Vuchic V.R. Urban transit system and technology. Hoboken, New Jersey: John Wiley \& Sons, 2007. 624 c.

18. Shavyraa Ch.D. Optimization methodology of interurban transport routes of automobile passenger transport / Shavyraa Ch.D., Kara-Sal B.S. // Международный научно-исследовательский журнал. 2018. № 6-2 (72). С. 64-66.

19. Постановление Правительства Российской Федерации № 641 от 25.08 .08 «Об оснащении транспортных, технических средств и систем аппаратурой спутниковой навигации ГЛОНАСС или ГЛОHACC/GPS».

20. Шавыраа Ч.Д. Диспетчерское управление движением автобусов // Мир транспорта. 2018. Т. 16. №6 (79). С. 146-152.

\section{References}

1. Vorob'ev A.I., Vlasenko G.V. Avtotransportnoe predpriyatie. 2013. № 8, pp. 27-29.

2. Gorev A.E. Informatsionnye tekhnologii na transporte. Elek-tronnaya identifikatsiya avtotransportnykh sredstv i transportnogo oborudovaniya [Transport information technology. Electronic identification of vehicles and transport equipment]. SPb., 2010.96 p. 
3. Gorev A.E. Putevoy navigator Izdatel'stvo: Assotsiatsiya "Nekommercheskoe partnerstvo "Obedinenie uchastnikov dorozhno-mostovoy otrasli "Dormost” (Sankt-Peterburg) [Travel Navigator Publisher: Association "Nonprofit Partnership" Unification of participants in the road and bridge industry "Dormost" (St. Petersburg)]. 2018, pp. 47-55.

4. Gorev A.E. Sbornik trudov № 17. Mezhdunarodnaya akademiya transporta [Collection of works № 17. International Academy of Transport], 2014, pp. 10-14.

5. Emel'yanova V.G. Aktual'nye voprosy tekhnicheskikh nauk (II): materialy mezhdunar. zaoch. nauch. konf.(g. Perm', fevral'2013 g.) [Actual problems of technical sciences (II): materials of Intern. in absentia scientific Conf. (Perm, February 2013)]. Perm': Merkuriy, 2013. IV, pp. $85-88$.

6. Zhankaziev S.V. Informatsionnye tekhnologii i innovatsii na transpor-te: materialy 2-oy Mezhdunarodnoy nauchno-prakticheskoy konferentsii [Information technologies and innovations in transport: materials of the 2nd International Scientific and Practical Conference]./ Ed. A.N. Novikov. 2016, pp. 3-9.

7. Larin O.N., Kazhaev A.A. Sovershenstvovanie marshrutnykh setey krupnykh gorodov [Improving the route networks of large cities]. Chelyabinsk: YuUrGU, 2013. 147 p.

8. Novikov A.N., Kulev A.V., Katunin A.A., Kulev M.V., Kuleva N.S. Mir transportnykh i tekhnologicheskikh mashin. 2015. № 3 (50), pp. 115-122.

9. Prikhod'ko V.M., Zhankaziev S.V. Na puti k avtonomnym trans-portnym sredstvam [On the way to autonomous vehicles]. M.: Izdatel'stvo "PERO". 2016. 152 p.

10. Shadrin S.S., Ivanov A.M. Avtotransportnoe predpriyatie. 2014. № 5.

11. VDO Automotive: http://www.hpw.ch/

12. MDV. http://www.mentzdv.de/en/

13. Best practice guide. Public transport -planning the Networks/Gustav Nielsen, 2005. Oslo: Hi-Trans 180 p.

14. Gorev A., Solodkij A. System Approach to Elimination of Traffic Jams in Large Cities in Russia. World Applied Sciences Journal 23 (8): 2013: pp. 1112-1117. 
15. Evaluation of bus priority strategies in coordinated traffic signai systems/Johan Wahlstedt. Royal institute of Technology, School of Architecture and the Built Environment, Department of Transport Science, Division of Traffic and Logistics. Stockholm: 2014. 181 p.

16. Huvarinen Y., Svatkova E., Oleshchenko E., Pushchina S. Road safety audit. Transportation Research Procedia 2017, pp. 236-241.

17. Vuchic V.R. Urban transit system and technology. Hoboken, New Jersey: John Wiley \& Sons, 2007. 624 c.

18. Shavuraa Ch.D., Kara-Sal B.S. Optimization methodology of interurban transport routes of automobile passenger transport. Mezhdunarodnyy nauchno-issledovatel'skiy zhurnal. 2018. № 6-2 (72), pp. 64-66.

19. Postanovlenie Pravitel’stva Rossiyskoy Federatsii № 641 ot 25.08 .08 «Ob osnashchenii transportnykh, tekhnicheskikh sredstv i sistem apparaturoy sputnikovoy navigatsii GLONASS ili GLO-NASS/GPS» [Decree of the Government of the Russian Federation No. 641 of August 25, 2008 "On the Equipment of Vehicles, Technical Means and Systems with GLONASS or GPS / GPS Satellite Navigation Equipment]. 20. Shavyraa Ch.D. Mir transporta. 2018. V. 16. №6 (79), pp. 146-152.

\section{ДАННЫЕ ОБ АВТОРЕ}

Шавыраа Чечек Деспи-ооловна, доцент кафедры «Транспортно-технологические средства, кандидат технических наук. ФГБОУ ВО Тувинский государственный университет ул. Ленина 36 г. Кызыл Республика Тыва, 667000, Российская Федераичия.

Shavyraa@mail.ru

\section{DATA ABOUT THE AUTHOR}

Shavyraa Chechek Despi-oolovna, Associate Professor of the Department of Transport and Technological Means, Candidate of Technical Sciences

Tuva State University

36, Lenin Str., Kyzyl, Republic of Tyva, 667000, Russian Federation Shavyraa@mail.ru 